\title{
Comparison Between Angiotensin-Converting Enzyme Inhibitors and Angiotensin Receptor Blockers for Incidence of Lung Cancer: A Retrospective Study
}

Pardeep Kumar ${ }^{1}$, Vinod Kumar ${ }^{2}$, FNU Murlidhar ${ }^{3}$, Aliya Fatima ${ }^{4}$, Maha Jahangir ${ }^{5}$, Dua Khalid 6 , Muhammad Khizar Memon ${ }^{7}$, Sidra Memon ${ }^{6}$, Besham Kumar ${ }^{4}$

1. Medicine, Jinnah Sindh Medical University, Karachi, PAK 2. Internal Medicine, Cleveland Clinic Abu Dhabi, Abu Dhabi, ARE 3. Internal Medicine, Chandka Medical College Hospital, Larkana, PAK 4. Internal Medicine, Jinnah Postgraduate Medical Centre, Karachi, PAK 5. Anesthesiology, Civil Hospital Karachi, Karachi, PAK 6. Internal Medicine, Jinnah Sindh Medical University, Karachi, PAK 7. Internal Medicine, Liaquat University of Medical and Health Sciences, Hyderabad, PAK

Corresponding author: Besham Kumar, beshamkumar916@gmail.com

\begin{abstract}
Introduction: Angiotensin-converting enzyme inhibitor (ACEI) and angiotensin II receptor blockers (ARBs) are taken as the first treatment option for hypertensive patients. The various global trials have suggested that ACEIs and ARBs may increase risk of lung cancer; however, the results are contradictory and there is no local study available. This study is conducted to compare the incidence of lung cancers in patients on ACEIs and ARBs.
\end{abstract}

Methods: This retrospective study, conducted in a major cardiology unit of a tertiary care hospital in Pakistan, included patients diagnosed with hypertension, between 2005 and 2010, who were prescribed either ACEIs or ARBs. During the period of 2005 to 2010, 47,823 naïve hypertensive patients were reported in the outpatient department of the cardiology unit. Of which, 22,241 were prescribed ACEI and 25,582 were prescribed ARBs. After sorting patient data based on our inclusion criteria, $n=14,891$ participants were included in the ACEI group and $n=19,112$ participants were included in the ARB group.

Results: The incidence of lung cancer in the ACEI and ARB group was $n=165$ and $n=160$, respectively. In this study, the overall incidence rates of lung cancer in the ACEI and ARB cohorts were 12.2 and 16.6 per 10,000 person-years, respectively. The hazard ratio was 1.32 (95\% confidence interval: 1.06-1.64; p-value: $0.01)$.

Conclusion: In this study, the incidence of lung cancer was relatively more among people using ACEIs than ARBs. Hence, patients undergoing long-term treatment with ACEIs need regular follow-up and proper scanning to avoid grave complications.

Review began 04/18/2021 Review ended 04/25/2021 Published 05/01/2021

\section{๑) Copyright 2021}

Kumar et al. This is an open access article distributed under the terms of the Creative Commons Attribution License CC-BY 4.0., which permits unrestricted use, distribution, and reproduction in any medium, provided the original author and source are credited.
Categories: Cardiology, Oncology, Pulmonology

Keywords: renin angiotensin alderosterone system, lung cancer, association, ace (angiotensin converting enzyme), angiotensin receptor blockers

\section{Introduction}

Angiotensin-converting enzyme inhibitors (ACEIs) and angiotensin II receptor blockers (ARBs) are drugs that block the body's renin-angiotensin-aldosterone system (RAS) and are usually taken as the first treatment option for hypertensive patients [1,2]. These drugs can also be used as a secondary treatment for heart failure, post-myocardial infarction and chronic kidney diseases [3]. Despite their common usage, some unfavorable effects of these medications such as anaphylactic reaction, angioedema, renal failure, jaundice and hepatitis, and hyperkalemia-induced arrhythmia cannot go unnoticed. Moreover, ACEIs are known to be associated with benign cough production. ACEI is also seen to cause higher lung cancer risk compared with ARB [4].

A recent study has demonstrated that ACEIs are known to increase the lung cancer risk by $14 \%$, compared with ARBs, which increased to $31 \%$ when ACEIs was used for 5 to 10 years. This is justified by the fact that it causes the accumulation of bradykinin and substance P (SP) in the alveoli of the lungs, which might potentially cause lung cancer [5]. Another research has also proven the fact that patients treated with ACEI were at an increased risk of lung cancer by 1.36 folds, whereas patients on ARB were at risk of 0.62 folds. This point towards the fact that patients who use ARB are less likely to get lung cancer compared with non-ARB users. [6]. However, data comparing ACEI and ARB for causing lung cancer are very limited from developing countries where ACEIs are frequently used to be a cheaper option; therefore, it is important to conduct a study to assess the incidence of lung cancer caused by these antihypertensive drugs. 


\section{Materials And Methods}

This retrospective study was conducted in a cardiology unit of three tertiary care hospital in Pakistan in March 2021. Data of patients diagnosed with hypertension between 2005 and 2010, who were prescribed either ACEIs or ARBs, were included in the study. Patients with less than five years of follow-up data were excluded from the study. Similarly, patients who switched medicine, from ACEI either to ARBs or vice versa were also excluded from the study. Permission to retrieve data of patients was taken from the ethical review board of the institute.

During the period of 2005 to 2010, 47,823 naïve hypertensive patients were reported in the outpatient department of the cardiology unit. Of which, 22,241 were prescribed ACEI and 25,582 were prescribed ARBs. After sorting patient data based on our inclusion criteria, $\mathrm{n}=14,891$ participants were included in the ACEI group and $\mathrm{n}=19,112$ participants were included in the ARB group (Figure 1).

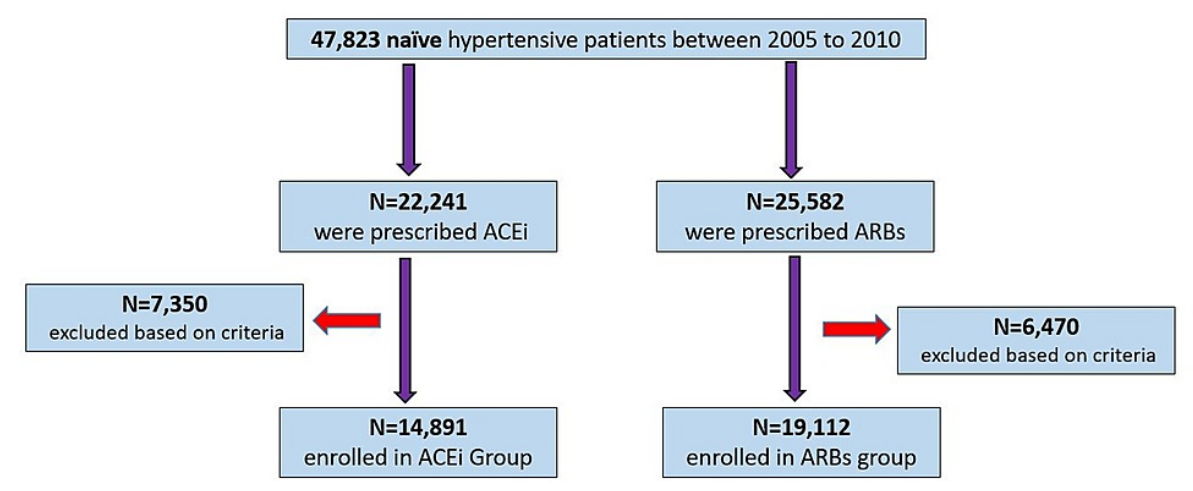

\section{FIGURE 1: Selection of Participants}

ACEl; Angiotensin-converting enzyme inhibitor. ARBs; Angiotensin receptor blockers

Age, gender, comorbidities, concomitant medication for hypertension and incidence of lung cancer was noted in the self-structured questionnaire. Statistical package for Social Sciences ${ }^{\circledR}$ software version 23.0 (SPSS; IBM Corp., Armonk, NY, USA) was used for data analysis. For numerical variables, data were expressed as mean \pm standard deviation. Frequencies and percentages were used for categorical variables. ACEI and ARB group's distribution of demographics, comorbidities and concomitant medication were compared. Differences were examined using Student's t-test for continuous variables and the chi-square test for categorical variables. We measured the survival probability in the ACEI and ARB cohorts using the Kaplan-Meier method. A p-value of less than 0.05 meant that there is a significant difference between the two groups and the null hypothesis is not valid.

\section{Results}

The mean age at the time of diagnosis of hypertension was in ACEI group was $49 \pm 11$ years and $50 \pm 13$ years in the ARB group. Comparison of further demographics is given in Table 1 . 


\section{Cureus}

Demographics of participants

Age at the time of diagnosis of hypertension (Mean \pm Standard Deviation)

Male

Smokers

Comorbidity

DM

CLD

CKD

Hyperlipidemia

Asthma

Stroke

MI

Concomitant Medications for Hypertension

Alpha blockers

Beta blockers

Calcium channel blockers

Diuretics

\section{ACEl group $(n=14,891)$}

ARB group $(n=19,112)$

P-value

$49 \pm 11$

$50 \pm 12$

NS

$7,854(52.74 \%)$

$10,781(56.41 \%)$

NS

$5,021(33.7 \%)$

$6,812(35.65 \%)$

NS

$7,652(51.39 \%)$

$10,856(56.80 \%) \quad$ NS

1,101 (7.39\%)

1,651 (8.64\%)

NS

$2,022(13.58 \%)$

$2,401(12.56 \%)$

NS

$6,078(40.82 \%)$

$7,998(41.85 \%)$

NS

$782(5.25 \%)$

$515(3.46 \%)$

$1,021(5.34 \%)$

NS

$600(3.14 \%)$

NS

1,254 (8.42\%)

$1,601(8.38 \%)$

NS

$131(8.81 \%)$

$6,052(40.64 \%)$

$1,721(9.00 \%)$

NS

$8,502(44.49 \%)$

NS

$10,112(67.91 \%)$

13,281 (69.49\%)

NS

$6,565(44.09 \%)$

\section{TABLE 1: Comparison of characteristics of patients undergoing treatment with ACEI or ARB}

ACEI: Angiotensin-converting enzyme inhibitor, ARB: Angiotensin receptor blocker, CLD: Chronic liver disease, CKD: Chronic kidney disease, DM: Diabetes mellitus, NS: non-significant, MI: Myocardial Infarction

The mean follow-up time was $7.01 \pm 3.02$ years and $7.12 \pm 3.35$ years in the ACEI and ARB group, respectively. The incidence of lung cancer in the ACEI and ARB group was $n=165$ and $n=160$, respectively. In this study, the overall incidence rate of lung cancer in the ACEI and ARB cohorts were 12.2 and 16.6 per 10,000 personyears, respectively. The hazard ratio was 1.32 (95\% confidence interval: 1.06-1.64; p-value: 0.01) (Table 2).

\begin{tabular}{|c|c|c|}
\hline & ACEl group $(n=14,891)$ & ARB group $(n=19,112)$ \\
\hline Follow up time in years (Mean $\pm S D$ ) & $7.01 \pm 3.02$ & $7.12 \pm 3.35$ \\
\hline Person years (No. of participants x Mean follow up time) & 104,385 & 136,077 \\
\hline Events (incidence of lung cancer) & 165 & 160 \\
\hline Rate (event per 10,000 person-year) & 15.86 & 11.7 \\
\hline Hazard ratio & 1.32 (p-value: 0.01) & 1 \\
\hline
\end{tabular}

TABLE 2: Comparison of follow-up and incidence of lung cancer in both groups

In Kaplan-Meier survival analysis, the survival probability of not having an event (lung cancer) was significantly higher in the ARB cohort than in the ACEI cohort (log-rank test, p-value $=0.002$ ). In both ACEI and ARB groups, increased exposure to ARBs and ACEIs was associated with an incidence of lung cancer. However, there was no difference between both groups (Table 3). 


\section{Cureus}

\begin{tabular}{|c|c|c|c|c|c|}
\hline $\begin{array}{l}\text { No. of years on } \\
\text { medication }\end{array}$ & $\begin{array}{l}\text { ACEl group (Events) } \\
(\mathrm{n}=165)\end{array}$ & $\begin{array}{l}\text { Intra group p- } \\
\text { value }\end{array}$ & $\begin{array}{l}\text { ARB group (Events) } \\
\text { ( } n=160)\end{array}$ & $\begin{array}{l}\text { Intragroup p- } \\
\text { value }\end{array}$ & $\begin{array}{l}\text { Intergroup p- } \\
\text { value }\end{array}$ \\
\hline 0-2 & $2(1.2 \%)$ & \multirow{6}{*}{$<0.00001$} & $1(0.6 \%)$ & \multirow{6}{*}{$<0.00001$} & \multirow{6}{*}{0.9} \\
\hline 2-4 & $11(6.6 \%)$ & & $9(5.6 \%)$ & & \\
\hline $4-6$ & $21(12.7 \%)$ & & $19(11.8 \%)$ & & \\
\hline 6-8 & 28 (16.9\%) & & 27 (16.8\%) & & \\
\hline $8-10$ & $45(27.2 \%)$ & & 50 (31.2\%) & & \\
\hline 10-12 & 65 (39.3\%) & & 54 (33.7\%) & & \\
\hline
\end{tabular}

TABLE 3: Comparison of incidence of development of lung cancer based on usage of medications over the number of years

\section{Discussion}

Our study demonstrates that the ACEI group is significantly more prone to getting lung cancer as compared to the ARB group. Kasper et al. in their study suggest that high cumulative ACEI doses may result in a modest increase in odds of lung cancer. However, they suggested lower dose showed no association [7].

On the contrary, two meta-analyses suggested no link between comparatively increased cancer risk and ACEIs because the events were found to be similar in both ARB and ACEI treated group and control group $[8,9]$. Bangalore et al. stated that patients treated with ACEI and ARB combination therapy were at a higher risk of cancer than those who were treated with only ACEI [8]. Conversely, the other proved that there was no increased cancer risk in patients who were treated with combination therapy and those with ACEI alone [9]. In these meta-analyses, the risk of cancer was associated more with combination therapy in three trials with longer follow-up time (mean $=48$ months) and showed more link with individual treatment in four trials with shorter follow-up time (mean $=32$ months) $[8,9]$. This suggests that confirmed findings to assess the outcomes of ARB and ACEI treatment would be obtained with a longer follow-up time. Another cohort study conducted in 2018, with a mean follow-up time of 6.4 years proved that ACEI had a stronger connection with causing lung cancer compared with ARB, which is consistent with the findings of our study [5].

The biological association between ACEIs and lung cancer has been explained by studies. Angiotensinconverting enzymes also metabolize bradykinin, a vasoactive substance known to be responsible for dilation [10]. Therefore, ACEI usage would lead to the accumulation of bradykinin in the lungs [11]. Bradykinin receptors have their sites on several cancerous tissues including lung cancer, and bradykinin can directly trigger the growth of lung cancer [11,12]. Bradykinin causes the release of vascular endothelial growth factor, which in turn would stimulate angiogenesis [13,14], and also indirectly affects lung cancer as it acts as a promoter of permeability of the vessels, by activating matrix metalloproteinase, which in turn leads to tumor invasion and metastases [14]. Additionally, ACEI causes the build-up of SP, which is usually observed in lung cancer and is known to be linked with angiogenesis and tumor proliferation [15].

Keeping in mind the aforementioned data, our study concluded that both antihypertensive drugs, ACEI and $\mathrm{ARB}$, are associated with an increased risk of lung cancer. In cases of continued usage, the doctors should do proper scanning of the lungs, via either x-ray or CT scan, at regular intervals to avoid any complications and late diagnosis. However, ideally, better alternatives should be suggested that do not have any major underlying side effects with longer use.

This study has several strengths. First, to our knowledge, with more than 20,000 patients followed for an average of seven years, this is the largest study to have been conducted to specifically assess this association in the local setting. Second, since it was a multi-center study, the sample was diverse. The study has several limitations as well. First, since it was a retrospective study, variables and information were limited. Second, even though smoking was considered, but information related to the number of packs per day was missing. Information on other confounding factors such as socio-economic status and occupational history were not available.

\section{Conclusions}

In this study, we found an elevated risk of lung cancer with the long-term use of ACEIs and ARBs for hypertension. However, this association was relatively more among people using ACEIs than ARBs. Hence, patients undergoing long-term treatment with these anti-hypertensives need regular follow-up and proper 
scanning to avoid grave complications. Moreover, a high index of suspicion is required in patients developing respiratory symptoms or symptoms pertaining to lung cancer.

\section{Additional Information \\ Disclosures}

Human subjects: Consent was obtained or waived by all participants in this study. Jinnah Sindh Medical University issued approval JMSU/IRB-OfC/R/03-12. Animal subjects: All authors have confirmed that this study did not involve animal subjects or tissue. Conflicts of interest: In compliance with the ICMJE uniform disclosure form, all authors declare the following: Payment/services info: All authors have declared that no financial support was received from any organization for the submitted work. Financial relationships: All authors have declared that they have no financial relationships at present or within the previous three years with any organizations that might have an interest in the submitted work. Other relationships: All authors have declared that there are no other relationships or activities that could appear to have influenced the submitted work.

\section{References}

1. Flack JM, Adekola B: Blood pressure and the new ACC/AHA hypertension guidelines. Trends Cardiovasc Med. 2020, 30:160-4. 10.1016/j.tcm.2019.05.003

2. Kovell LC, Ahmed HM, Misra S, Whelton SP, Prokopowicz GP, Blumenthal RS, McEvoy JW: US hypertension management guidelines: a review of the recent past and recommendations for the future. J Am Heart Assoc. 2015, 4:e002315. 10.1161/JAHA.115.002315

3. Xue Y, Sun S, Cai J, et al.: Effects of ACEI and ARB on COVID-19 patients: a meta-analysis . J Renin Angiotensin Aldosterone Syst. 2020, 21:1470320320981321. 10.1177/1470320320981321

4. Wakelee HA, Chang ET, Gomez SL, et al.: Lung cancer incidence in never smokers. J Clin Oncol. 2007, 25:472-8. 10.1200/JCO.2006.07.2983

5. Hicks BM, Filion KB, Yin H, Sakr L, Udell JA, Azoulay L: Angiotensin converting enzyme inhibitors and risk of lung cancer: population based cohort study. BMJ. 2018, 363:k4209. 10.1136/bmj.k4209

6. Lin SY, Lin CL, Lin CC, et al.: Association between angiotensin-converting enzyme inhibitors and lung cancer-A nationwide, population-based, propensity score-matched cohort study. Cancers (Basel). 2020, 12:747. 10.3390/cancers12030747

7. Kristensen KB, Hicks B, Azoulay L, Pottegård A: Use of ACE (angiotensin-converting enzyme) inhibitors and risk of lung cancer: a nationwide nested case-control study. Circ Cardiovasc Qual Outcomes. 2021, 14:e006687. 10.1161/CIRCOUTCOMES.120.006687

8. Bangalore S, Kumar S, Kjeldsen SE, et al.: Antihypertensive drugs and risk of cancer: network meta-analyses and trial sequential analyses of 324,168 participants from randomised trials. Lancet Oncol. 2011, 12:65-82. 10.1016/S1470-2045(10)70260-6

9. Effects of telmisartan, irbesartan, valsartan, candesartan, and losartan on cancers in 15 trials enrolling 138,769 individuals. J Hypertens. 2011, 29:623-35. 10.1097/HJH.0b013e328344a7de

10. Carey RM, Siragy HM: Newly recognized components of the renin-angiotensin system: potential roles in cardiovascular and renal regulation. Endocr Rev. 2003, 24:261-71. 10.1210/er.2003-0001

11. Trifilieff A, Da Silva A, Gies JP: Kinins and respiratory tract diseases. Eur Respir J. 1993, 6:576-87.

12. Golias Ch, Charalabopoulos A, Stagikas D, Charalabopoulos K, Batistatou A: The kinin system--bradykinin: biological effects and clinical implications. Multiple role of the kinin system--bradykinin. Hippokratia. 2007, 11:124-8.

13. Ishihara K, Hayash I, Yamashina S, Majima M: A potential role of bradykinin in angiogenesis and growth of S-180 mouse tumors. Jpn J Pharmacol. 2001, 87:318-26. 10.1254/jip.87.318

14. Stewart JM: Bradykinin antagonists as anti-cancer agents. Curr Pharm Des. 2003, 9:2036-42. $10.2174 / 1381612033454171$

15. Lever AF, Hole DJ, Gillis CR, et al.: Do inhibitors of angiotensin-I-converting enzyme protect against risk of cancer?. Lancet. 1998, 352:179-84. 10.1016/S0140-6736(98)03228-0 